\title{
Design Optimization of Crush Beams of SUV Chassis for Crashworthiness
}

\author{
Ramesh Koora ${ }^{1}$, Ramavath Suman ${ }^{2}$, Syed Azam Pasha Quadri ${ }^{3}$ \\ ${ }^{1}$ PG Scholar, LIET, Survey No.32, Himayathsagar, Hyderabad, 500091, India \\ ${ }^{2}$ Assistant Professor, LIET, Survey No.32, Himayathsagar, Hyderabad, 500091, India \\ ${ }^{3}$ Professor, LIET, Survey No.32, Himayathsagar, Hyderabad, 500091, India
}

\begin{abstract}
Every year Insurance Companies throughout the world pay out huge sums of money in motor claims. A significant proportion of this payment relates to the repair of damaged Vehicles. Returning the vehicle to its pre-accident condition on behalf of the policyholder is a costly and time consuming business and quite naturally insurers have striven to control this cost over the years. To achieve this objective the International Insurance Industry has always looked to its Research Organizations in various parts of the world to help in the fight to reduce or at least contain these repair costs. This tends to stringent requirements for Geometric Packaging in order to maintain adequate space for Managing Energy at the time of accidents or collisions. The general department of vehicle structural design for Energy Management at the time of crash involves three major areas, Front structure, Body and side structure and Rear structure. Perhaps the greatest challenge is the Front structure Design. The structure needs to be maintained enough space inside the vehicle so that the occupant resistance can operate effectively. The present study is to improve the overall safety, security, and quality and to reduce the cost of repair of motor vehicle during accidents by proper design of the crush beams of SUV chassis. These crush beams are energy absorbing bumpers and should be able to crush during impacts without dissipating the energy to the structure of the vehicle. The added advantage comes with the reduced weight thus providing greater fuel economy to the vehicle and has greater protection.
\end{abstract}

Keywords: Chassis, Crash, Crashworthiness, Crush Beams, LS Dyna.

\section{Introduction}

Since the late 1970s, the Federal New Car Assessment Program has compared Frontal crashworthiness among new passenger vehicles. This program, which involves $40 \mathrm{mph}$ crash tests into a full-width rigid barrier, has been highly successful in providing consumers with comparative crashworthiness information. It also has been a major contributor to the crashworthiness improvements that characterize recent passenger vehicle models. The very success of the New Car Assessment Program means remaining differences in performance among most new vehicles in full-width tests are small. This doesn't mean important crashworthiness differences no longer exist. They do exist, and additional crash test configurations can highlight these differences. One such test is the frontal offset crash

The Institute began frontal offset crash testing in 1995. In the Institute's $40 \mathrm{mph}$ offset test, 40 percent of the total width of each vehicle strikes a barrier on the driver side. The barrier's deformable face is made of aluminum honeycomb, which makes the forces in the test similar to those involved in a frontal offset crash between two vehicles of the same weight; each going just less than $40 \mathrm{mph}$. Test results can be compared only among vehicles of similar weight. Like fullwidth crash test results, the results of offset tests cannot be used to compare vehicle performance across weight classes. This is because the kinetic energy involved in the frontal test depends on the speed and weight of the test vehicle, and the crash is more severe for heavier vehicles. Given equivalent frontal ratings for heavier and lighter vehicles, the heavier vehicle typically will offer better protection in real-world crashes.

\section{Crashworthiness}

Vehicle crashworthiness is the ability of the vehicle and restraint systems to reduce occupant injury. Crash avoidance technologies are not included in this definition. Examples of crash avoidance improvements to automobiles include antilock brakes, improved tires, and traction control, which improve the driver's chance of avoiding a crash or to recover from a driving error. When a crash is unavoidable, it is the crash energy and the manner in which vehicle occupant's experience the associated forces that will determine the extent of injury to those occupants. Vehicle crashworthiness reduces the magnitude of the forces experienced by the occupants, with the goal of reducing them to below the threshold for severe injury.

The Institute began frontal offset crash testing in 1995. In the Institute's $40 \mathrm{mph}$ offset test, 40 percent of the total width of each vehicle strikes a barrier on the driver side. The barrier's deformable face is made of aluminum honeycomb, which makes the forces in the test similar to those involved in a frontal offset crash between two vehicles of the same weight, each going just less than $40 \mathrm{mph}$. Test results can be compared only among vehicles of similar weight. Like fullwidth crash test results, the results of offset tests cannot be used to compare vehicle performance across weight classes. This is because the kinetic energy involved in the frontal test depends on the speed and weight of the test vehicle, and the crash is more severe for heavier vehicles. Given equivalent frontal ratings for heavier and lighter vehicles, the heavier 


\section{International Journal of Science and Research (IJSR) \\ ISSN (Online): 2319-7064}

Index Copernicus Value (2013): 6.14 | Impact Factor (2014): 5.611

vehicle typically will offer better protection in real-world crashes.

The probability of injury or fatality is a function of the type of impact. The crashworthiness of the vehicle is implemented in such a way that specific design features are incorporated for specific impact directions, i.e. crumple zones in the front of the vehicle for frontal impact, side impact beams for side impact, and so on.

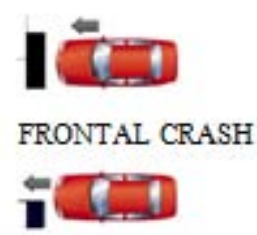

OFFSET CRASH

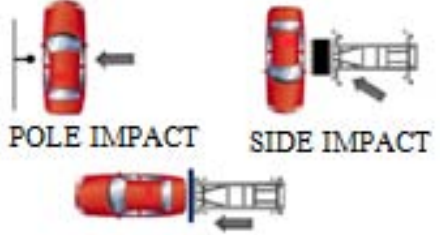

REAR CRASH
Figure 1: Various events of crash impacts

\subsection{Types of Crash}

The probability of injury or fatality is a function of the type of impact. The crashworthiness of the vehicle is implemented in such a way that specific design features are incorporated for specific impact directions, i.e. crumple zones in the front of the vehicle for frontal impact, side impact beams for side impact, and so on.

\subsubsection{Frontal Impact}

Frontal impact is the most common type of crash. Statistics from NHTSA indicate that $51 \%$ of impacts resulting in injury or fatalities are fontal collisions. The act that frontal crashes are the most common is the reason that the earliest crashworthiness research focused on this type of collision. Although $51 \%$ of crashes resulting in fatalities or injury are frontal collisions, they account for only $31 \%$ of fatalities. This indicates that some success has ken achieved in the improvement of the crashworthiness of vehicles for this type of impact.

\subsubsection{Side Impact}

Side impacts are less common than frontal crashes, comprising $25 \%$ of collisions resulting in injury or fatality. On the other hand, they account for $34 \%$ of the fatalities, indicating that protecting drivers from side impact is more difficult than fontal impact. This is likely because of the comparatively smaller crumple volume available to absorb energy is this type of impact.

\subsubsection{Roll Over}

As with side-impact, rollover accidents have a disproportionately high fatality rate. NHTSA statistics indicate that $15 \%$ of accidents resulting in injury or fatality are rollover. However, they are responsible for $33 \%$ of the fatalities. The fatalities due to rollover are almost always due to the fact that the occupant is ejected from the vehicle, the occupants were wearing seatbelts in only $13 \%$ of the fatality cases.

\subsubsection{Rear Impact}

Rear impacts account for a small percentage of vehicle collisions, and are usually low speed impacts. Fatality rates for this type of impact are low, only $2 \%$ of fatalities are caused by rear impact. Whiplash is the most common injury resulting from this type of impact, but the injury mechanism is not well understood.

\section{Crash Energy Management}

Automotive vehicle structural crashworthiness is defined as the capability of an automotive structure to provide adequate protection for the vehicle and its passengers in the event of a crash. The vehicle structure and the occupant restraint system interact to protect vehicle occupants. The structure needs to maintain enough space inside the vehicle so that the occupant restraints can operate effectively

Currently, three Federal Motor Vehicle Safety Standards (FMVSS) must be met by vehicles sold in the U.S:

- 208 Frontal impact at \pm 30 o and Flat Frontal Impact

- 214 Dynamic impacts

- 301 Frontals, lateral and rear

Sheet steel products constitute the principal material used in automotive vehicle structures. The material properties of sheet steel have a major influence on the vehicle structural crashworthiness performance and its energy absorption capability.

\subsection{Factors Affecting Crash Energy Management}

The main energy management components, such as longitudinal rails that provide the major portion of the energy absorption, undergo large plastic deformations. The work hardening effect and strain rate sensitivity of the material, as well as dynamic instability of the rails must be considered in their design. There are stringent requirements for geometric packaging in order to fit in the components, while attempting to maintain crush space for managing crash energy. Frequently this results in a complex structure, and adequate strength and structural stability becomes very difficult to achieve. To overcome these obstacles, designers need to pursue novel concepts and solutions, both in structural design and packaging of vehicle components. In order to maintain minimum vehicle mass, the structure cannot be over designed.

\subsection{Dynamic Crash Sequence}

The desirable dynamic crash sequence is progressive in nature. The initial contactor (bumper or side) deforms first, then the next structural component, and the following component until the energy is absorbed. Each section involved in the crash must exhibit enough resistance to the load transmitted from the previous section so that plastic deformation of the previous section can dissipate energy. The body compartment must be designed to withstand the anticipated crush loads for the various defined impact speeds from defined impact directions with adequate body integrity to allow for proper function of the restraint system. In designing the structural components for progressive crush, the effect of crush velocity and section stability on the anticipated crush force must be considered. 


\section{International Journal of Science and Research (IJSR) \\ ISSN (Online): 2319-7064}

Index Copernicus Value (2013): 6.14 | Impact Factor (2014): 5.611

\subsection{Rail Crush Modes}

The longitudinal rails in the vehicle structure form the major force path in the Energy Management of a vehicle during a crash. These components are also the most difficult to modify after the vehicle packaging and architecture concepts are completed. These considerations imply that the crash energy absorbing capability of the major structural rails should be included as part of the vehicle design specifications. Since energy is the product of force times crush distance, the "ideal" rail compression mode would be a continuous axial compression with no bending.

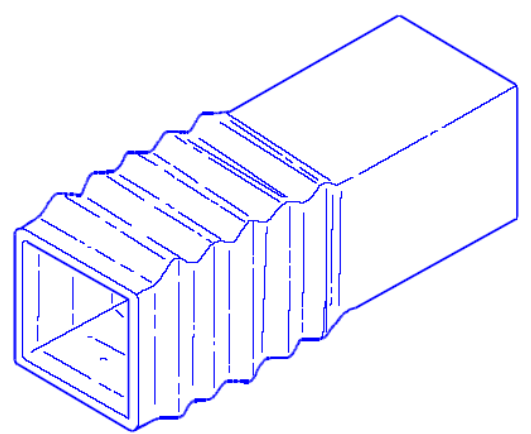

Figure 2: Ideal collapse of a Crush beam or Rails

Pre-convoluting the rails, with the convolutions progressively becoming deeper toward the point of load application, reduces the peak loading and provides for axial compression with high energy absorbing efficiency. An example of a front rail with this configuration is shown in Figures $2 \& 3$.

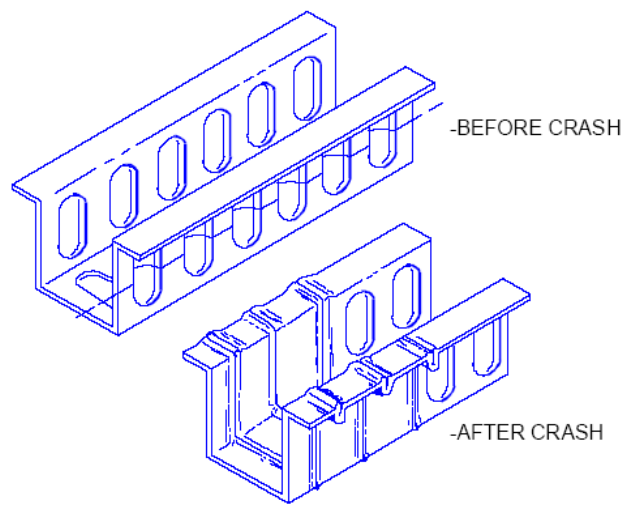

Figure 3: Crush Beam or Front Rails Pre-Convoluted

A premature loss of energy absorption capacity will alter the crash behavior of the vehicle, many times in an unpredictable manner. In combination with crush initiators, some internal reinforcement or spacers may be added to the interior of the rail to keep the walls apart, thus delaying the hinge effect by increasing the bending moment capability of the rail section. This will impose some mass and cost penalty, but additional reinforcement is usually necessary to meet performance requirements.

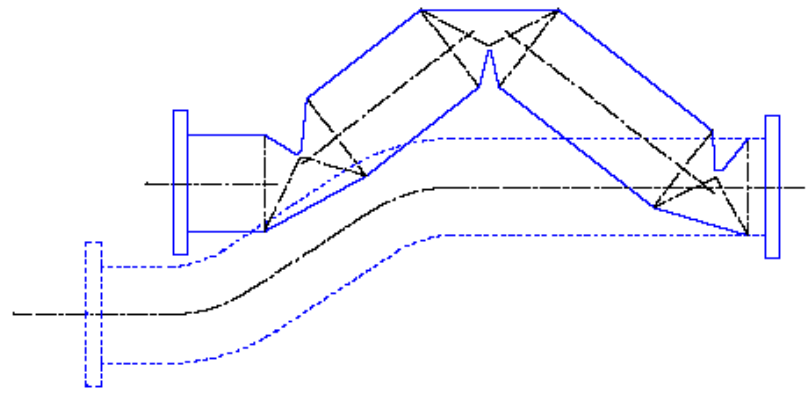

Figure 4: Schematic illustration of bending in a frame rail

\section{Description of the Crush Beams}

Chassis is also known as Skelton of a vehicle. It supports the whole body and passenger weight. Crush beams are attached to both sides of the chassis, which are used for absorbing the energy during Impacts or collision. Following are the various points considered while attaching a Crush beams to Nissan Titan chassis.

- The lengths of both inner and outer crush beams are $450 \mathrm{~mm}$ and have U shape cross-section. Crush beams are made of mild steel.

- The width of beams is of varying or taper cross-section. The width of the crush beam is more at front rails and less at bumper attachments (towards the front of vehicle). The width of the outer crush beam varies from $135 \mathrm{~mm}$ to $120 \mathrm{~mm}$. The width of inner crush beam varies from $130 \mathrm{~mm}$ to $115 \mathrm{~mm}$. The width of the outer beam is $5 \mathrm{~mm}$ more than the inner for creation of lap weld between them. After welding these two crush-beams form a box cross-section.

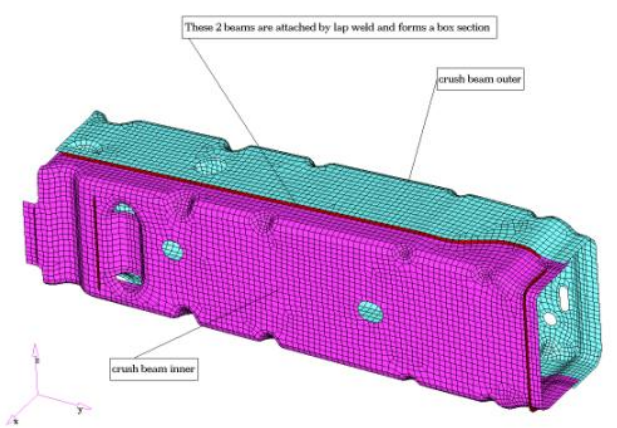

Figure 5: FE Model of lap weld between inner and outer crush

- One end (more width) of the crush beams is attached to the front rail of the chassis by lap weld and other end (less width) of the crush beams are attached to the bumper of the car by $\mathrm{T}$ weld. The attachment of the various components of chassis is done with triangular ( 3 node) elements in FEM as shown in Figure 5.4. The thickness of the weld is taken as $5 \mathrm{~mm}$ for simulation. 


\section{International Journal of Science and Research (IJSR) \\ ISSN (Online): 2319-7064}

Index Copernicus Value (2013): 6.14 | Impact Factor (2014): 5.611

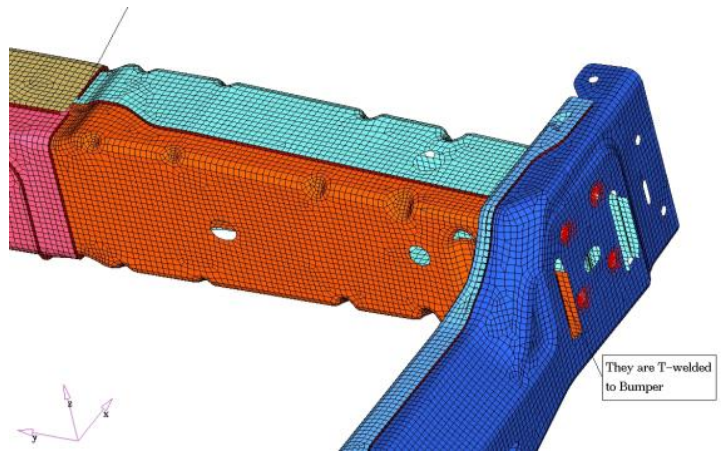

Figure 6: FE Model of crush beams welds between front rails and bumpers

- The various section planes are created in the chassis to find the transmission of force at various locations. The output of the crash analysis is obtained by getting the Graph for

Force Vs. Time or Acceleration Vs. Displacement at various section Planes. The area under the under the force or displacement curve is the energy absorbed.

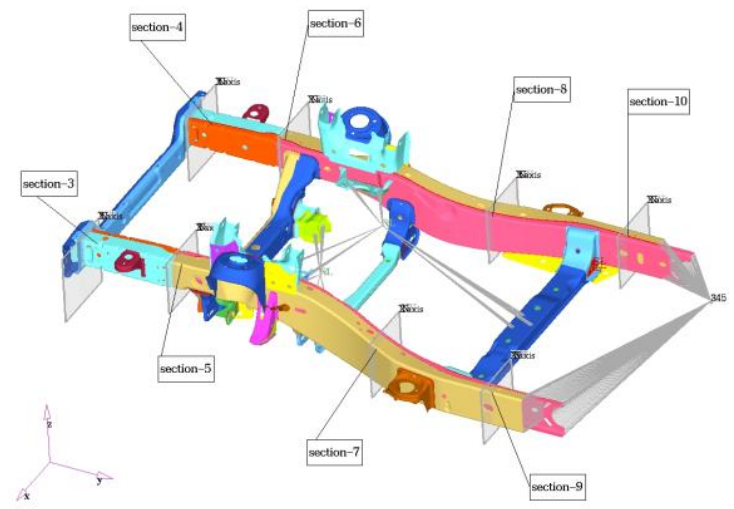

Figure 7: Section Planes created in the chassis frame to get Force Vs Time Graph

\section{Various Proposals of crash beam to improve the Crashworthiness}

\subsection{Baseline Model of Crush beam}

This is the final model of the Energy absorption bumper (crush beam) of Nissan Titan Frame, which is passing the test for full frontal crash analysis requirement. Therefore this model has to be tested for offset crash analysis and should be optimized for better design. The offset crash analysis is more complicated than the frontal impact as the participation of the crush beam is only on one side. The thickness is $3.2 \mathrm{~mm}$

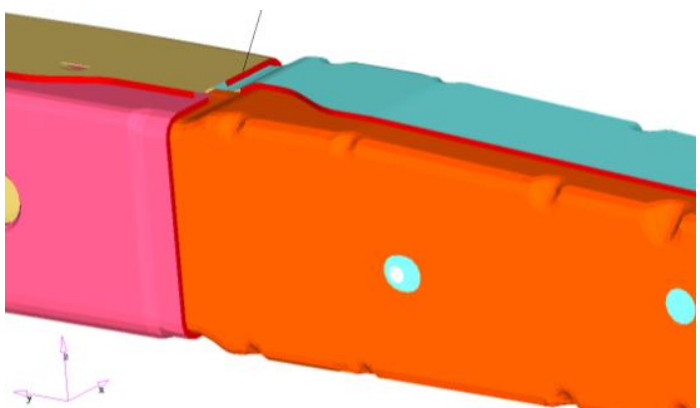

Figure 8: Proposal 1: Baseline Model of Crush beam

\subsection{Increased cross-section of the crush beam at the rail attachment area}

In this proposal the crush beams are lap welded onto the rails. This is the critical area in crash analysis. The purpose of increasing the cross section is to collapse the crush beam completely. The energy transmission to the cabin starts from the front rail. Cross-section area is one of the parameter, which affects the crush force. The thickness is $3.2 \mathrm{~mm}$.

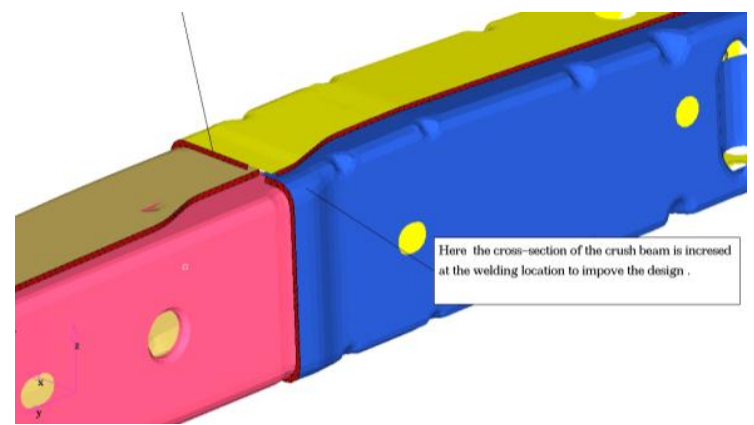

Figure 9: Proposal 2: Increased cross-section at the front rail end of crush beam

\subsection{Proposal 3: Base Line model with Reinforcement}

In this proposal an extra reinforcement with $3.2 \mathrm{~mm}$ thickness is added at the weld location between the rails and crash beams. The purpose of using the reinforcement is to improve the Baseline design. This reinforcement is lap welded to both rails and crash beams. It is also bolted to the crash beam outer to increase the rigidity at the weld location. The main purpose of the reinforcement is to prevent deformation in the rails.

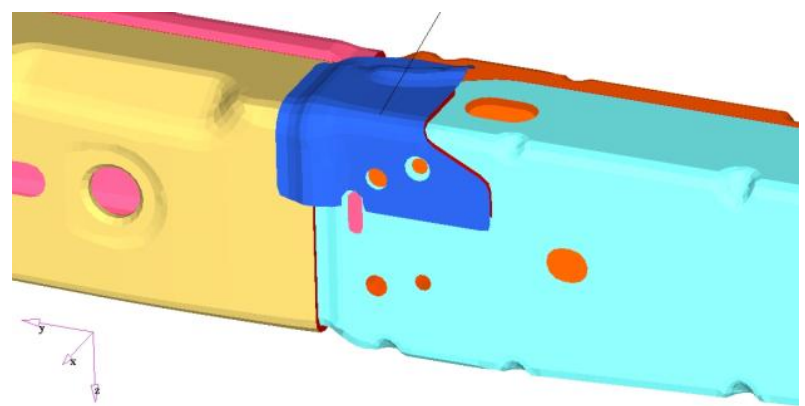

Figure 10: Proposal 3: Base Line model with Reinforcement of $3.2 \mathrm{~mm}$ thickness

\subsection{Proposal 3: Base Line model with Reinforcement.}

In this proposal both inner and outer crush beams of baseline design were replaced with the Tailor Rolled Blanks. The thickness is varied from $3.0 \mathrm{~mm}$ to $3.8 \mathrm{~mm}$ from front to rear of the crush beams. The purpose of using the Tailor rolled blanks is to have a gradual stiffness increase in the crush beams and to avoid lateral bending in the beams. 


\section{International Journal of Science and Research (IJSR) \\ ISSN (Online): 2319-7064}

Index Copernicus Value (2013): 6.14 | Impact Factor (2014): 5.611

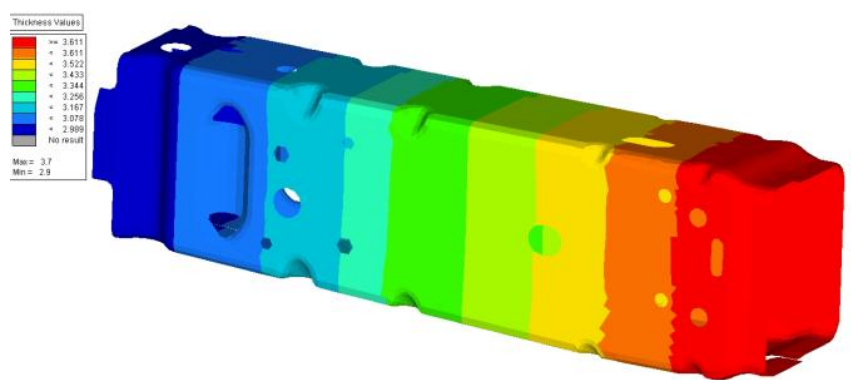

Figure 11: Proposal 4: Tailor Rolled Blanks crush tips with thickness varying from $3.0 \mathrm{~mm}$ to $3.8 \mathrm{~mm}$

\section{FEA Results and Discussion}

\subsection{Force Vs. Time Graph}

The data generated at the various section planes provides some insight into the structural response characteristics of the vehicle. The Force Vs. Time graph gives the variation of force transmission at the various locations of the chassis frame as shown in fundamental model. When the load is generated, axial collapse or bending deformation occurs. In the case of axial collapse, the load is stabilized and held nearly constant. In contrast, during bending deformation, the load declines rapidly when the maximum load is exceeded. Thus, if the transition to bending deformation can be controlled, then it is possible to reduce the load at the desired time during the crash. These Graphs are obtained from the LS-PrePost Post Processor.

\section{At Section No. 3}

This section is the starting zone of crush beam. The axial collapse for the Proposal 1, Proposal 3 and Proposal 4 are identical at the initial stages with a force of $245 \mathrm{kN}$ approximately. But the buckling deformation (collapse) is good for the Proposal 4 in comparison to other proposals at the final stage. The variable thickness in the proposal 4 is to keep the walls apart, thus delaying the hinge effect by increasing the bending moment capability of the rail section. The reinforcement at the end of the crush beam will increase the cycle time and cost of the product. Tailor Rolled Blank will not increase the assembly cycle time, but will impose cost penalty, but this is necessary to meet performance requirements.

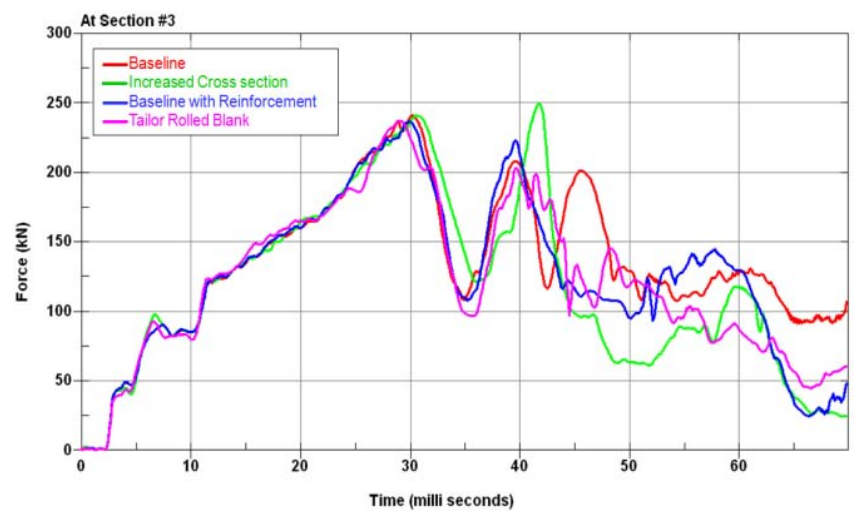

Figure 12: Force Vs. Time at Section Plane No. 3

\section{At Section No. 5}

This section is the starting zone for front rail of the chassis. From Fig. 13. we can conclude that, the Proposal 1 and Proposal 4 are identical with restriction force of $240 \mathrm{kN}$ (Fig. 13.) approximately. In the middle and at the final stage Proposal 4 has the high resistance force of $300 \mathrm{kN}$ (Fig.13.) before bending deformation of rails. The deformation in the rails is less for in proposal Tailor Rolled Blank, and the driver's cabin is safer with less deformation.

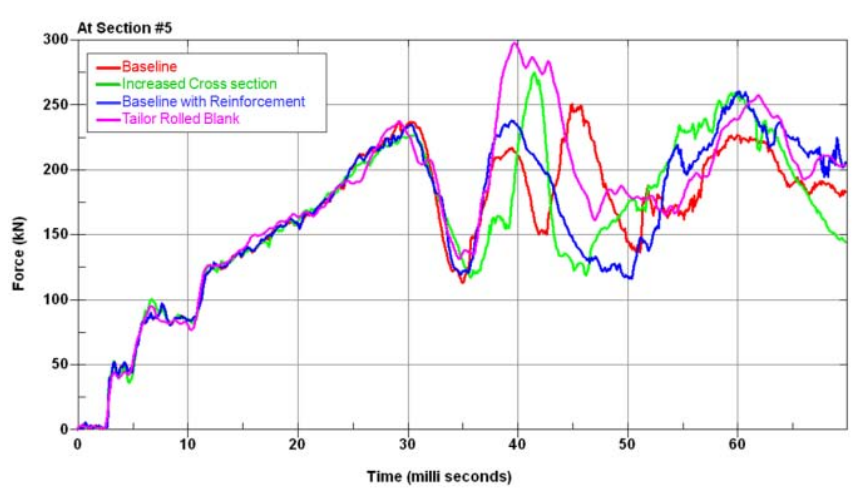

Figure 13: Force Vs. Time at Section Plane No. 5

\section{At Section No. 7}

This section is located at the starting zone of the driver's cabin. At this section deformation need to be less from the point of safety of driver. And at this zone the deformation is similar to the baseline proposal, with a maximum resistance force of $200 \mathrm{kN}$ (Fig. 14.). The deformation of the safety cage and intrusion into the compartment, then the restraint systems are less and keep the injuries low to the driver during crash.

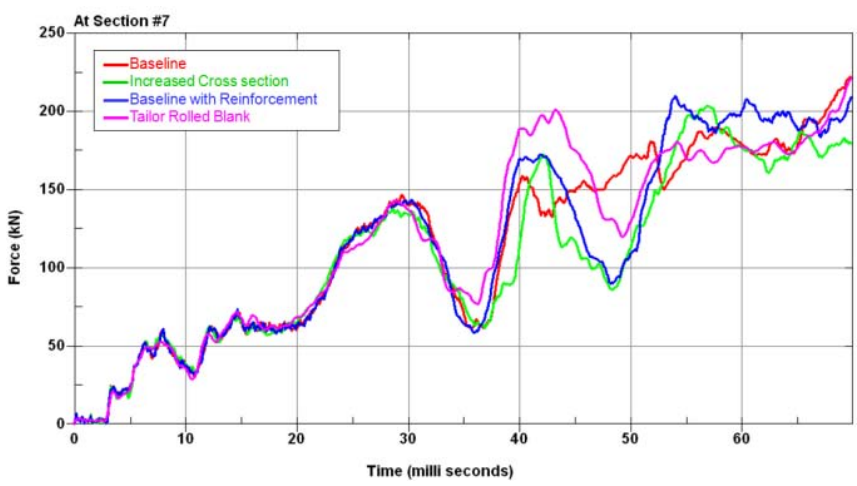

Figure 14: Force Vs. Time at Section Plane No. 7

\section{At Section No. 9}

This section is located inside the driver's cabin. Considering the safety of passengers in drivers cabin the deformation need to be less. At this zone the deformation is similar to the baseline proposal. Therefore this proposal No.4 has strong occupant compartment. If the compartment remains largely intact, then the restraint systems can control the motion of the driver and help keep injury measures low. 


\section{International Journal of Science and Research (IJSR) \\ ISSN (Online): 2319-7064}

Index Copernicus Value (2013): 6.14 | Impact Factor (2014): 5.611

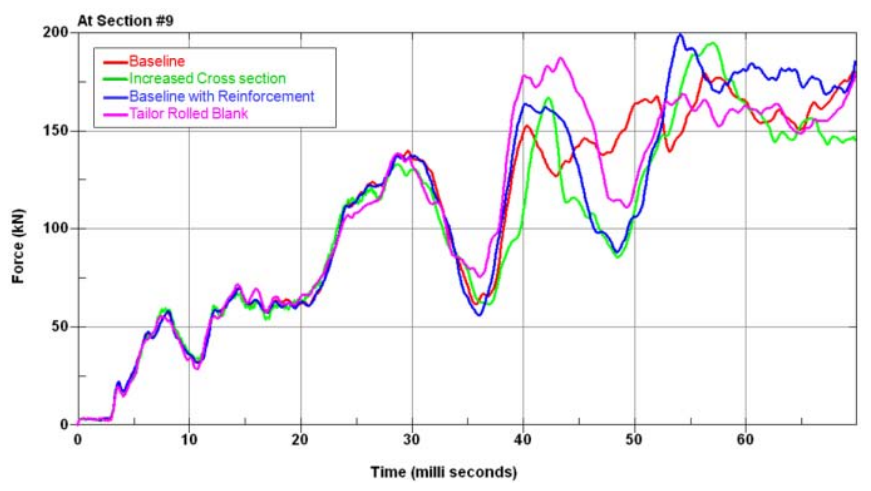

Figure 15: Force Vs. Time at Section Plane No. 9

\subsection{Energy Absorbed by Crush beams}

The following are the energy absorbed by the crush beam for different proposals. The absorbed energy is measures at the section plane No.5 which was placed at the end of the crush beams.

\begin{tabular}{|c|c|c|}
\hline Proposal & Description & Energy absorbed $(J)$ \\
\hline Proposal 1 & Baseline Model & 11423 \\
\hline Proposal 2 & Increased Cross section & 11394 \\
\hline Proposal 3 & Baseline with Reinforcement & 11507 \\
\hline Proposal 4 & Tailor Rolled Blanks & 12196 \\
\hline
\end{tabular}

\section{Conclusions}

Among all the listed proposals the one with Tailor Rolled Blanks has more energy absorption indicates the more safety of occupants.

From the above comparisons of modes of Force Vs. Time plots and energy absorption table, we can conclude that Tailor Rolled Blanks crush beams of Proposal 4 shown in Fig.13. is the better design when compared to other proposals and study shows that drivers of vehicles that earn good ratings in frontal offset crash tests have significantly lower risk of fatal injuries in real-world frontal crashes, compared with drivers of vehicles with poor ratings. To ensure that real-world risks continue to diminish, we've got to preserve the vehicle design improvements that have been made in response to our frontal crash analysis program.

\section{References}

[1] Fischer, R., "Occupant Protection In Car To Car Impacts", SAE Technical Paper No. 740316 (1974).

[2] Magee, C.L. Keynote Address "Design for Crash Energy Management - Present and Future Developments", The Seventh International Conference on Vehicle Structural Mechanics, April 1988

[3] Johnson, W. and Mamalis, A.G., Crashworthiness of Vehicles, Mechanical Engineering publications, London, 1978

[4] Langseth, M. and Hopperstad, O.S., "Static and Dynamic Axial Crushing of Square Thin-Walled Aluminum and steel Extrusions ", International Journal of Impact Engineering, 18(7), pp. 949-968, 1996.
[5] Woo Jong Kang, Hoon Huh, Crash analysis of thinwalled structures with an elasto-plastic finite element method. Key Engineering Materials, v177-180, ptl, 2000.

[6] Robert D. Cook, Finite element modeling for stress analysis

[7] http://www.iihs.org/ratings/frontal_test_info 